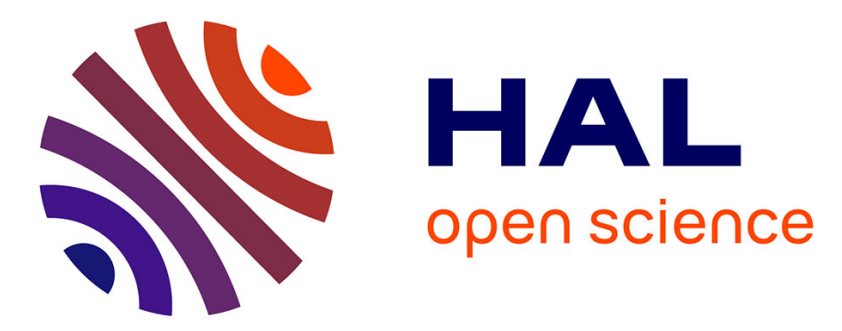

\title{
Species boundaries of Gulf of Mexico vestimentiferans (Polychaeta, Siboglinidae) inferred from mitochondrial genes
}

Maria Pia Miglietta, Stéphane Hourdez, Dominique A. Cowart, Stephen W. Schaeffer, Charles Fisher

\section{To cite this version:}

Maria Pia Miglietta, Stéphane Hourdez, Dominique A. Cowart, Stephen W. Schaeffer, Charles Fisher. Species boundaries of Gulf of Mexico vestimentiferans (Polychaeta, Siboglinidae) inferred from mitochondrial genes. Deep Sea Research Part II: Topical Studies in Oceanography, 2010, 57 (21-23), pp.1916-1925. 10.1016/j.dsr2.2010.05.007 . hal-01250940

\section{HAL Id: hal-01250940 \\ https://hal.science/hal-01250940}

Submitted on 5 May 2020

HAL is a multi-disciplinary open access archive for the deposit and dissemination of scientific research documents, whether they are published or not. The documents may come from teaching and research institutions in France or abroad, or from public or private research centers.
L'archive ouverte pluridisciplinaire HAL, est destinée au dépôt et à la diffusion de documents scientifiques de niveau recherche, publiés ou non, émanant des établissements d'enseignement et de recherche français ou étrangers, des laboratoires publics ou privés. 


\title{
Species boundaries of Gulf of Mexico vestimentiferans (Polychaeta, Siboglinidae) inferred from mitochondrial genes
}

\author{
Maria Pia Miglietta ${ }^{\mathrm{a}, *}$, Stephane Hourdez ${ }^{\mathrm{b}}$, Dominique A. Cowart ${ }^{\mathrm{a}}$, Stephen W. Schaeffer ${ }^{\mathrm{a}}$, \\ Charles Fisher ${ }^{\mathrm{a}}$
}

a The Pennsylvania State University, Department of Biology, 208 Mueller Lab, University Park, PA 16802-5301, USA

${ }^{\mathrm{b}}$ Station Biologique de Roscoff, CNRS-UPMC, BP74, 29680 Roscoff, France

\begin{abstract}
At least six morphospecies of vestimentiferan tubeworms are associated with cold seeps in the Gulf of Mexico (GOM). The physiology and ecology of the two best-studied species from depths above $1000 \mathrm{~m}$ in the upper Louisiana slope (Lamellibrachia luymesi and Seepiophila jonesi) are relatively well understood. The biology of one rare species from the upper slope (escarpiid sp. nov.) and three morphospecies found at greater depths in the GOM (Lamellibrachia sp. 1, L. sp. 2, and Escarpia laminata) are not as well understood. Here we address species distributions and boundaries of cold-seep tubeworms using phylogenetic hypotheses based on two mitochondrial genes. Fragments of the mitochondrial large ribosomal subunit rDNA (16S) and cytochrome oxidase subunit I (COI) genes were sequenced for 167 vestimentiferans collected from the GOM and analyzed in the context of other seep vestimentiferans for which sequence data were available. The analysis supported five monophyletic clades of vestimentiferans in the GOM. Intra-clade variation in both genes was very low, and there was no apparent correlation between the within-clade diversity and collection depth or location. Two of the morphospecies of Lamellibrachia from different depths in the GOM could not be distinguished by either mitochondrial gene. Similarly, E. laminata could not be distinguished from other described species of Escarpia from either the west coast of Africa or the eastern Pacific using COI. We suggest that the mitochondrial COI and $16 \mathrm{~S}$ genes have little utility as barcoding markers for seep vestimentiferan tubeworms.
\end{abstract}

\section{Introduction}

For the better part of the last century, marine biologists assumed oceans were largely interconnected by currents that enabled larvae and propagules to reach distant shores and assure gene flow even over great distances. More recently, the use of molecular tools has challenged assumptions regarding population structure and speciation in the ocean and demonstrated that marine animals often have genetically distinct populations despite geographic proximity (Palumbi and Warner, 2003). Although sharp genetic breaks between close populations have been recorded throughout the ocean, most of what is known about speciation patterns and phylogeography has been inferred from shallow-water and coastal systems, which represent only about $15 \%$ of the aquatic environment. Thus, our knowledge of processes that lead to population divergence and speciation in the

\footnotetext{
* Corresponding author.

E-mail address: mp.miglietta@psu.edu (M. Pia Miglietta).
}

open ocean is relatively limited (Thornhill et al., 2008, and references therein; Zardus et al., 2006).

Vestimentiferan tubeworms, which include 10 genera in the polychaete family Siboglinidae (Halanych et al., 2001; Kojima et al., 2002; McMullin et al., 2003; Rouse, 2001), are abundant at deep-sea hydrothermal vents and cold seeps at depths ranging from 80 to $9345 \mathrm{~m}$ (Cordes et al., 2007b; Mironov, 2000; Miura et al., 2002). In the deep Gulf of Mexico, six morphospecies have been reported (Cordes et al., 2009). Two described species, Lamellibrachia luymesi (van der Land and Narrevang, 1975) and Seepiophila jonesi (Gardiner et al., 2001), are relatively well studied, and their ecology and physiology are well understood (Bergquist et al., 2002; Cordes et al., 2007a, b). They occur on the upper Louisiana slope at between $\sim 500$ and $950 \mathrm{~m}$ depth and occasionally co-occur with a rare undescribed species, escarpiid sp. nov. The three other morphological species are found on the lower Louisiana slope at depths greater than about $950 \mathrm{~m}$ (Lamellibrachia sp. 1, L. sp. 2, and Escarpia laminata).

In this paper, we present phylogenetic hypotheses based on the mitochondrial large ribosomal subunit rDNA gene (16S) and mitochondrial cytochrome oxidase 1 gene (COI) of over 200 
vestimentiferans (sequenced for either or both genes) including 180 individuals from the six morphospecies that occur in the Gulf of Mexico. Phylogenetic trees are used to examine the distribution of vestimentiferans in the Gulf of Mexico and their relations to other vestimentiferans around the world. We examined the concordance between the morphological and phylogenetic data to identify differences between the genealogical and morphological species analyzed. Finally, we compared between- and within-species $16 \mathrm{~S}$ and COI genetic distances and show that these two mitochondrial genes have little utility as "barcoding molecules" for vestimentiferans.

\section{Material and methods}

\subsection{Collection of material}

Vestimentiferans were collected in the deep Gulf of Mexico from 12 sites on two cruises in 2006 and 2007, using the DSV ALVIN and R.V. Atlantis in 2006 and ROV JASON II and the NOAA ship Ronald Brown in 2007 (see Fig. 1). Vestimentiferans were collected using either the Bushmaster Jr. collection device (for samples destined also for community ecology analyses, see Cordes et al., 2010) or the submersible manipulators and placed directly into a collection box. Aboadship, all vestimentiferans were identified using morphological criteria, and subsamples of vestimentum tissue were frozen for subsequent analyses at the Pennsylvania State University. Additional frozen vestimentiferan tissue samples collected previously from shallower sites on the upper Louisiana slope using the DSV JOHNSON SEA LINK were also analyzed for this study (see Table 1 for a complete list of specimens).

\subsection{DNA sequencing}

DNA was extracted either by boiling a small amount of frozen tissue in $600 \mu \mathrm{L}$ of $10 \%$ Chelex solution (Bio-Rad) or using a CTAB+PVP method modified from Doyle and Doyle (1987), followed by a standard ethanol precipitation.

A 524 bp fragment of the mitochondrial 16S gene was amplified using primers 16Sar and 16Sbr (Kojima et al., 1995). A 689 bp fragment of the mitochondrial gene COI was amplified using the primers HCO and LCO (Folmer et al., 1994). Amplification was performed under the following PCR conditions: $94{ }^{\circ} \mathrm{C}$ ( $\left.1 \mathrm{~min}\right)$; $50{ }^{\circ} \mathrm{C}$ (2 min); and $72{ }^{\circ} \mathrm{C}$ (2.5 min) for 30 cycles. All PCR reactions were performed using $0.5 \mu \mathrm{l}$ of each primer, $2.5 \mu \mathrm{l}$ of $10 \mathrm{XBuffer}$, $2 \mu \mathrm{l}$ of $10 \mu \mathrm{M}$ dNTPs, $0.2 \mu \mathrm{l}$ of taq, $16.5 \mu \mathrm{l}$ of water, and $3 \mu \mathrm{l}$ of template. The PCR product was first purified with the ExoSap-it protocol (USB, Affimetrix) and then run on a $2 \%$ agarose gel stained with ethidium bromide to enable us to check the quantity and quality of the product. The purified PCR product was used as a template for double-stranded sequencing that was carried out at the Pennsylvania State University Sequencing Core Facility, University Park, Pennsylvania, using ABI 3730 sequencer machines.

\subsection{Phylogenetic analysis}

Sequences were first assembled and edited using Geneious Pro 4.0.4 (Biomatters Ltd.), and then aligned using ClustalX (Thompson et al., 2002). All alignments were confirmed and edited visually in MacClade 4.06 OS X (Maddison and Maddison, 2000) to insure that indel variation was aligned consistently among all sequenced genes.

Phylogenetic analyses of the aligned sequences were conducted using the maximum parsimony (MP) optimality criterion and neighbor joining (Saitou and Nei, 1987) (NJ) in PAUP* version 4.0b10 for Macintosh (Wilgenbusch and Swofford, 2003), and the maximum likelihood (ML) optimality criterion in GARLI v0.951.OsX-GUI (Zwickl, 2006) and PhylML (Guindon and Gascuel, 2003). The best-fit model used in PhyML and PAUP* was assessed using the akaike information criterion as implemented in modeltest (Posada, 2003; Posada and Crandall, 1998). The best-fit model was $(\mathrm{HKY}+\mathrm{I}+\mathrm{G})$ for the COI dataset and $(\mathrm{GTR}+\mathrm{G})$ for the $16 \mathrm{~S}$ dataset. Clade stability was assessed by ML bootstrap analysis (Felsenstein, 1985) in GARLI (100 bootstrap replicates) and $\mathrm{NJ}$ (1000 replicates) in PAUP*. The ML analyses in GARLI were performed using random starting trees and default termination conditions. Within- and between-species distances were estimated in MEGA 4 (Tamura et al., 2007).

\section{Results}

The complete COI dataset includes 146 sequences (Table 1 ) of the six Gulf of Mexico (GOM) cold-seep morphospecies, the available GenBank sequences of E. southwardae, E. spicata, and assorted Lamellibrachia species from around the world. Sequences from the hydrothermal vent-dwelling genera Riftia, Oasisia, Tevnia, and Arcovestia were used as outgroups. We restricted our analyses to

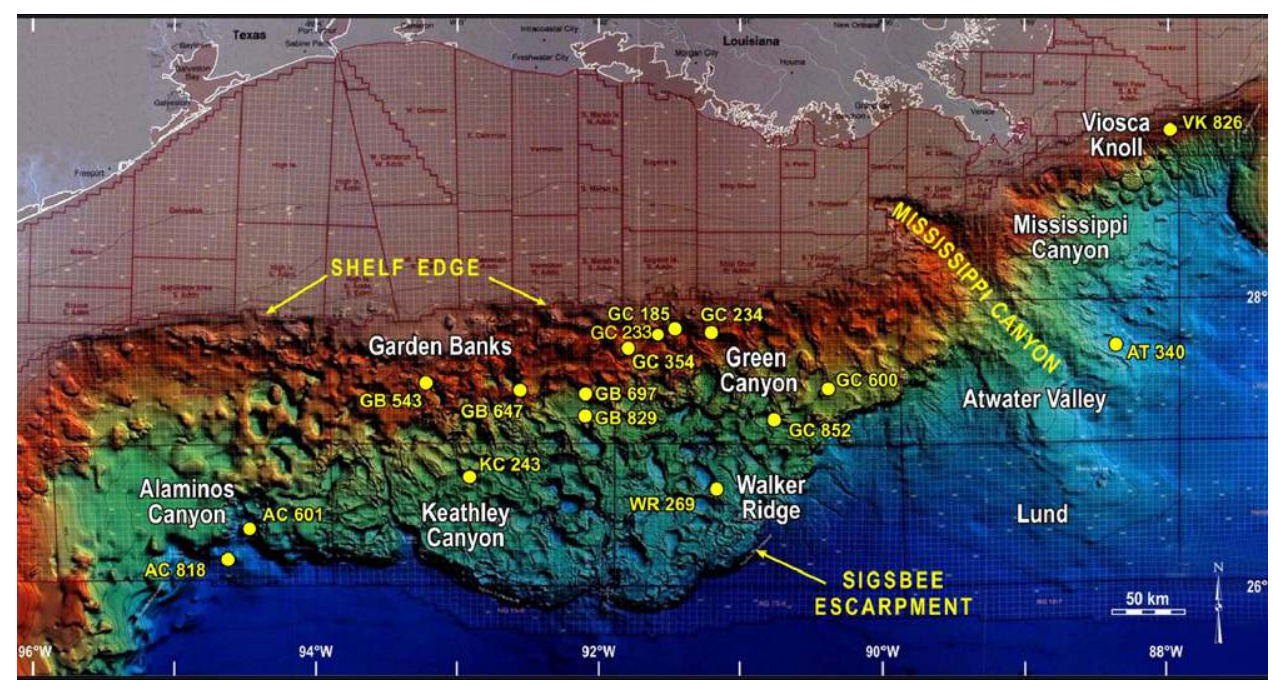

Fig. 1. Map of new deep-water collection sites in the Gulf of Mexico. 
Table 1

Genbank accension numbers and genes analyzed.

\begin{tabular}{|c|c|c|c|c|}
\hline Sample $^{\mathrm{a}}$ & Clade & Location $^{\text {b }}$ & GenBank Accession \# & Genes \\
\hline 1.AC818 & Escarpia laminate & GOM AC818 & $\begin{array}{l}\text { 16S: GU068165 } \\
\text { COI: GU059163 }\end{array}$ & $16 \mathrm{~S} / \mathrm{COI}$ \\
\hline 2.AC818 & Escarpia laminata & GOM AC818 & COI: GU059196 & COI \\
\hline 3.AC818 & Escarpia laminata & GOM AC818 & $\begin{array}{l}\text { 16S: GU068166 } \\
\text { COI: GU059205 }\end{array}$ & $16 \mathrm{~S} / \mathrm{COI}$ \\
\hline 4.AC818 & Escarpia laminata & GOM AC818 & $\begin{array}{l}\text { 16S: GU068167 } \\
\text { COI: GU059214 }\end{array}$ & $16 \mathrm{~S} / \mathrm{COI}$ \\
\hline 5.AC818 & Escarpia laminata & GOM AC818 & $\begin{array}{l}\text { 16S: GU068168 } \\
\text { COI: GU059222 }\end{array}$ & $16 \mathrm{~S} / \mathrm{COI}$ \\
\hline 6.AC818 & Escarpia laminata & GOM AC818 & $\begin{array}{l}\text { 16S: GU068169 } \\
\text { COI: GU059228 }\end{array}$ & $16 \mathrm{~S} / \mathrm{COI}$ \\
\hline 7.AC818 & Escarpia laminata & GOM AC818 & $\begin{array}{l}\text { 16S: GU068170 } \\
\text { COI: GU059234 }\end{array}$ & $16 \mathrm{~S} / \mathrm{COI}$ \\
\hline 8.AC818 & Lamellibrachia luymesi/sp. 1 & GOM AC818 & 16S: GU068171 & $16 S$ \\
\hline 10.GB697 & Escarpia laminata & GOM GB697 & $\begin{array}{l}\text { 16S: GU068172 } \\
\text { COI: GU059164 }\end{array}$ & $16 \mathrm{~S} / \mathrm{COI}$ \\
\hline 11.GB829 & Escarpia laminata & GOM GB829 & $\begin{array}{l}\text { 16S: GU068173 } \\
\text { COI: GU059170 }\end{array}$ & $16 \mathrm{~S} / \mathrm{COI}$ \\
\hline 12.GB829 & Escarpia laminata & GOM GB829 & $\begin{array}{l}\text { 16S: GU068174 } \\
\text { COI: GU059174 }\end{array}$ & $16 \mathrm{~S} / \mathrm{COI}$ \\
\hline 13.GC600 & Escarpia laminata & GOM GC600 & 16S: GU068175 & $16 \mathrm{~S}$ \\
\hline 14.GC852 & Escarpia laminata & GOM GC852 & $\begin{array}{l}\text { 16S: GU068176 } \\
\text { COI: GU059185 }\end{array}$ & $16 \mathrm{~S} / \mathrm{COI}$ \\
\hline 17.GC852 & Escarpia laminata & GOM GC852 & $\begin{array}{l}\text { 16S: GU068177 } \\
\text { COI: GU059192 }\end{array}$ & $16 \mathrm{~S} / \mathrm{COI}$ \\
\hline 18.GC852 & Escarpia laminata & GOM GC852 & COI: GU059193 & COI \\
\hline 19.GC852 & Escarpia laminata & GOM GC852 & $\begin{array}{l}\text { 16S: GU068178 } \\
\text { COI: GU059194 }\end{array}$ & $16 \mathrm{~S} / \mathrm{COI}$ \\
\hline 19B.AC818 & Escarpia laminata & GOM AC 818 & COI: GU059195 & $\mathrm{COI}$ \\
\hline 20.WR269 & Escarpia laminata & GOM WR269 & $\begin{array}{l}\text { 16S: GU068179 } \\
\text { COI: GU059197 }\end{array}$ & $16 \mathrm{~S} / \mathrm{COI}$ \\
\hline 21.WR269 & Escarpia laminata & GOM WR269 & $\begin{array}{l}\text { 16S: GU068180 } \\
\text { COI: GU059198 }\end{array}$ & $16 \mathrm{~S} / \mathrm{COI}$ \\
\hline 22.WR269 & Escarpia laminata & GOM WR269 & $\begin{array}{l}\text { 16S: GU068181 } \\
\text { COI: GU059199 }\end{array}$ & $16 \mathrm{~S} / \mathrm{COI}$ \\
\hline 23.WR269 & Escarpia laminata & GOM WR269 & COI: GU059200 & $\mathrm{COI}$ \\
\hline 24.WR269 & Escarpia laminata & GOM WR269 & COI: GU059201 & $\mathrm{COI}$ \\
\hline 26.АТ340 & Escarpia laminata & GOM AT340 & 16S: GU068182 & $16 \mathrm{~S}$ \\
\hline 27.АТ340 & Escarpia laminata & GOM АT340 & $\begin{array}{l}\text { 16S: GU068183 } \\
\text { COI: GU059202 }\end{array}$ & $16 \mathrm{~S} / \mathrm{COI}$ \\
\hline 28.АТ340 & Escarpia laminata & GOM AT340 & $\begin{array}{l}\text { 16S: GU068184 } \\
\text { COI: GU059203 }\end{array}$ & $16 \mathrm{~S} / \mathrm{COI}$ \\
\hline 29.АТ340 & Escarpia laminata & GOM AT340 & $\begin{array}{l}\text { 16S: GU068185 } \\
\text { COI: GU059204 }\end{array}$ & $16 \mathrm{~S} / \mathrm{COI}$ \\
\hline 30.АТ340 & Escarpia laminata & GOM AT340 & $\begin{array}{l}\text { 16S: GU068186 } \\
\text { COI: GU059206 }\end{array}$ & $16 \mathrm{~S} / \mathrm{COI}$ \\
\hline 31.AT340 & Escarpia laminata & GOM AT340 & $\begin{array}{l}\text { 16S: GU068187 } \\
\text { COI: GU059207 }\end{array}$ & $16 \mathrm{~S} / \mathrm{COI}$ \\
\hline 32.AT340 & Escarpia laminata & GOM AT340 & $\begin{array}{l}\text { 16S: GU068188 } \\
\text { COI: GU059208 }\end{array}$ & $16 \mathrm{~S} / \mathrm{COI}$ \\
\hline 33.АТ340 & Escarpia laminata & GOM AT340 & $\begin{array}{l}\text { 16S: GU068189 } \\
\text { COI: GU059209 }\end{array}$ & $16 \mathrm{~S} / \mathrm{COI}$ \\
\hline 34.WR264 & Escarpia laminata & GOM WR269 & 16S: GU068190 & $16 S$ \\
\hline 35.WR269 & Escarpia laminata & GOM WR269 & $\begin{array}{l}\text { 16S: GU068191 } \\
\text { COI: GU059210 }\end{array}$ & $16 \mathrm{~S} / \mathrm{COI}$ \\
\hline 37.AC601 & Escarpia laminata & GOM AC601 & $\begin{array}{l}\text { 16S: GU068192 } \\
\text { COI: GU059211 }\end{array}$ & $16 \mathrm{~S} / \mathrm{COI}$ \\
\hline 38.AC601 & Escarpia laminata & GOM AC601 & $\begin{array}{l}\text { 16S: GU068193 } \\
\text { COI: GU059212 }\end{array}$ & $16 \mathrm{~S} / \mathrm{COI}$ \\
\hline 39.AC601 & Escarpia laminata & GOM AC601 & $\begin{array}{l}\text { 16S: GU068194 } \\
\text { COI: GU059213 }\end{array}$ & $16 \mathrm{~S} / \mathrm{COI}$ \\
\hline 40.AC601 & Escarpia laminata & GOM AC601 & $\begin{array}{l}\text { 16S: GU068195 } \\
\text { COI: GU059215 }\end{array}$ & $16 \mathrm{~S} / \mathrm{COI}$ \\
\hline 41.AC601 & Escarpia laminata & GOM AC601 & 16S: GU068196 & $16 \mathrm{~S}$ \\
\hline 42.AC601 & Escarpia laminata & GOM AC602 & $\begin{array}{l}\text { 16S: GU068197 } \\
\text { COI: GU059216 }\end{array}$ & $16 \mathrm{~S} / \mathrm{COI}$ \\
\hline 43.AC601 & Escarpia laminata & GOM AC601 & $\begin{array}{l}\text { 16S: GU068198 } \\
\text { COI: GU059217 }\end{array}$ & $16 \mathrm{~S} / \mathrm{COI}$ \\
\hline 44.AC601 & Escarpia laminata & GOM AC602 & $\begin{array}{l}\text { 16S: GU068199 } \\
\text { COI: GU059218 }\end{array}$ & $16 \mathrm{~S} / \mathrm{COI}$ \\
\hline 45.AC601 & Escarpia laminata & GOM AC601 & $\begin{array}{l}\text { 16S: GU068200 } \\
\text { COI: GU059219 }\end{array}$ & $16 \mathrm{~S} / \mathrm{COI}$ \\
\hline 46.АТ340 & Escarpia laminata & GOM AT340 & 16S: GU068201 & $16 S$ \\
\hline 47.AC601 & Escarpia laminata & GOM AC601 & $\begin{array}{l}\text { 16S: GU068202 } \\
\text { COI: GU059220 }\end{array}$ & $16 \mathrm{~S} / \mathrm{COI}$ \\
\hline
\end{tabular}


Table 1 (continued)

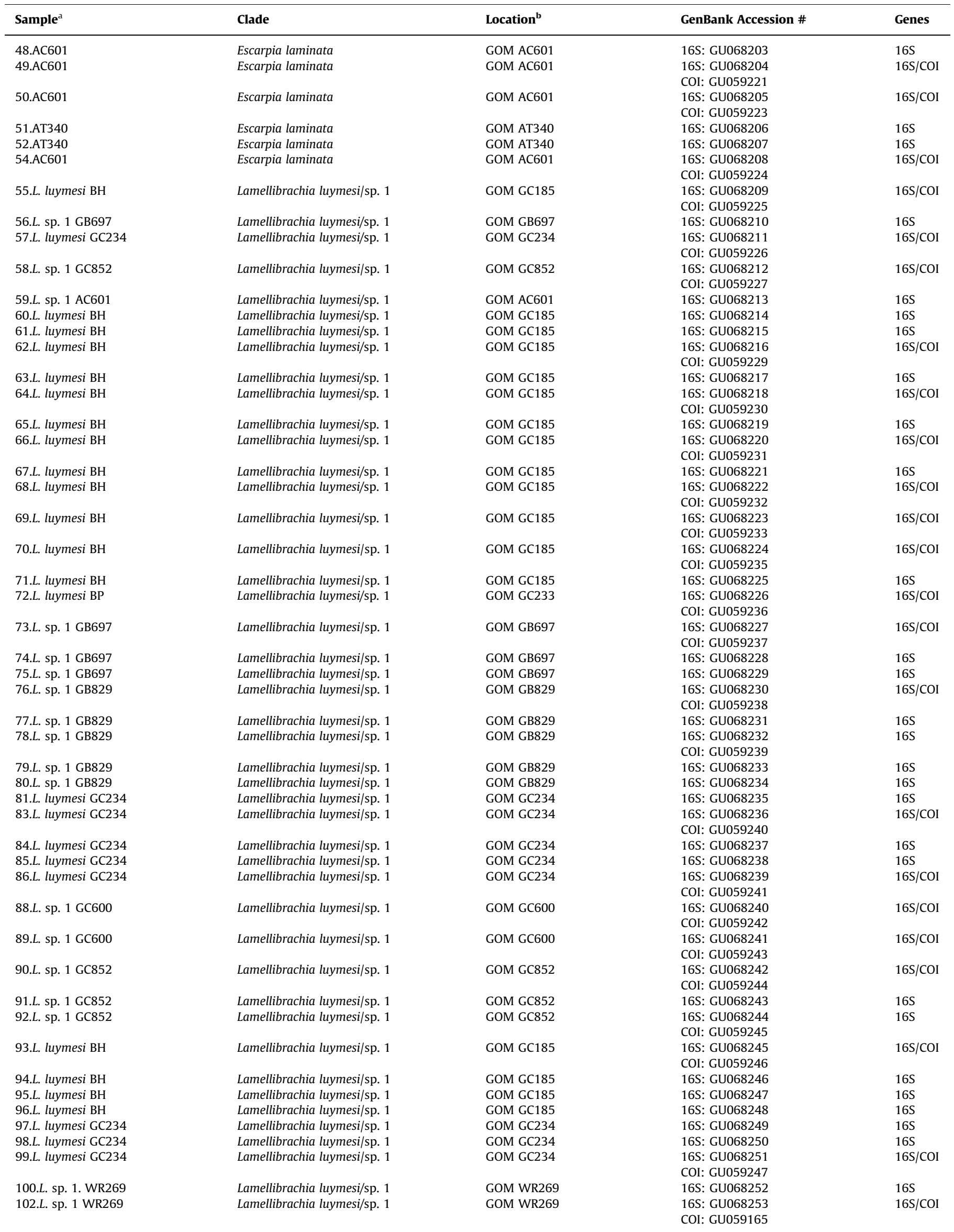


Table 1 (continued)

\begin{tabular}{|c|c|c|c|c|}
\hline Sample $^{\mathrm{a}}$ & Clade & Location $^{\text {b }}$ & GenBank Accession \# & Genes \\
\hline 103.L. sp. 1 АТ 340 & Lamellibrachia luymesi/sp. 1 & GOM AT340 & $\begin{array}{l}\text { 16S: GU068254 } \\
\text { COI: GU059166 }\end{array}$ & $16 \mathrm{~S} / \mathrm{COI}$ \\
\hline 104.L. sp. 1 WR269 & Lamellibrachia luymesi/sp. 1 & GOM WR269 & $\begin{array}{l}\text { 16S: GU068255 } \\
\text { COI: GU059167 }\end{array}$ & $16 \mathrm{~S} / \mathrm{COI}$ \\
\hline 105.L. sp. 1 WR269 & Lamellibrachia luymesi/sp. 1 & GOM WR269 & $\begin{array}{l}\text { 16S: GU068256 } \\
\text { COI: GU059168 }\end{array}$ & $16 \mathrm{~S} / \mathrm{COI}$ \\
\hline 107.L. sp. 1 AC601 & Lamellibrachia luymesi/sp. 1 & GOM AC601 & $\begin{array}{l}\text { 16S: GU068257 } \\
\text { COI: GU059169 }\end{array}$ & $16 \mathrm{~S} / \mathrm{COI}$ \\
\hline 110.L. sp. 1 AC601 & Lamellibrachia luymesi/sp. 1 & GOM AC601 & $\begin{array}{l}\text { 16S: GU068258 } \\
\text { COI: GU059171 }\end{array}$ & $16 \mathrm{~S} / \mathrm{COI}$ \\
\hline 112.GB697 & Lamellibrachia sp. 2 & GOM GB697 & 16S: GU068259 & $16 S$ \\
\hline 113.GB697 & Lamellibrachia sp. 2 & GOM GB697 & $\begin{array}{l}\text { 16S: GU068260 } \\
\text { COI: GU059172 }\end{array}$ & $16 \mathrm{~S} / \mathrm{COI}$ \\
\hline 114.GB697 & Lamellibrachia sp. 2 & GOM GB297 & 16S: GU068261 & $16 S$ \\
\hline 115.GB697 & Lamellibrachia sp. 2 & GOM GB297 & 16S: GU068262 & $16 S$ \\
\hline 116.GB829 & Lamellibrachia sp. 2 & GOM GB829 & 16S: GU068263 & $16 S$ \\
\hline 117.GC600 & Lamellibrachia sp. 2 & GOM GC600 & 16S: GU068264 & $16 \mathrm{~S}$ \\
\hline 118.GC852 & Lamellibrachia sp. 2 & GOM GC852 & $\begin{array}{l}\text { 16S: GU068265 } \\
\text { COI: GU059173 }\end{array}$ & $16 \mathrm{~S} / \mathrm{COI}$ \\
\hline 119.GC852 & Lamellibrachia sp. 2 & GOM GC852 & 16S: GU068266 & $16 S$ \\
\hline 120.GC852 & Lamellibrachia sp. 2 & GOM GC852 & 16S: GU068267 & $16 \mathrm{~S}$ \\
\hline 121.WR269 & Lamellibrachia sp. 2 & GOM WR269 & 16S: GU068268 & $16 \mathrm{~S}$ \\
\hline 122.АТ340 & Lamellibrachia sp. 2 & GOM АT340 & $\begin{array}{l}\text { 16S: GU068269 } \\
\text { COI: GU059175 }\end{array}$ & $16 \mathrm{~S} / \mathrm{COI}$ \\
\hline 123.WR2695 & Lamellibrachia sp. 2 & GOM WR269 & $\begin{array}{l}\text { 16S: GU068270 } \\
\text { COI: GU059176 }\end{array}$ & $16 \mathrm{~S} / \mathrm{COI}$ \\
\hline 124.AC601 & Lamellibrachia sp. 2 & GOM AC601 & COI: GU059177 & $\mathrm{COI}$ \\
\hline 126.AC601 & Lamellibrachia sp. 2 & GOM AC601 & COI: GU059178 & $\mathrm{COI}$ \\
\hline 128.L. sp. 1 АТ 340 & Lamellibrachia luymesi/sp. 1 & GOM AT340 & $\begin{array}{l}\text { 16S: GU068271 } \\
\text { COI: GU059179 }\end{array}$ & $16 \mathrm{~S} / \mathrm{COI}$ \\
\hline 130.GB697 & Seepiophila jonesi & GOM GB697 & $\begin{array}{l}\text { 16S: GU068272 } \\
\text { COI: GU059180 }\end{array}$ & $16 \mathrm{~S} / \mathrm{COI}$ \\
\hline 131.GB647 & Seepiophila jonesi & GOM GB647 & $\begin{array}{l}\text { 16S: GU068273 } \\
\text { COI: GU05981 }\end{array}$ & $16 \mathrm{~S} / \mathrm{COI}$ \\
\hline 132.GC234 & Seepiophila jonesi & GOM GC234 & $\begin{array}{l}\text { 16S: GU068274 } \\
\text { COI: GU059182 }\end{array}$ & $16 \mathrm{~S} / \mathrm{COI}$ \\
\hline 133.GC234 & Seepiophila jonesi & GOM GC234 & 16S: GU068275 & $16 \mathrm{~S}$ \\
\hline 134.GC234 & Seepiophila jonesi & GOM GC234 & $\begin{array}{l}\text { 16S: GU068276 } \\
\text { COI: GU059183 }\end{array}$ & $16 \mathrm{~S} / \mathrm{COI}$ \\
\hline 134b.GC234 & Seepiophila jonesi & GOM GC234 & $\begin{array}{l}\text { 16S: GU068277 } \\
\text { COI: GU059184 }\end{array}$ & $16 \mathrm{~S} / \mathrm{COI}$ \\
\hline 135.GC234 & Seepiophila jonesi & GOM GC234 & 16S: GU068278 & $16 S$ \\
\hline 136.GC234 & Seepiophila jonesi & GOM GC234 & 16S: GU068279 & $16 S$ \\
\hline 137.BH & Seepiophila jonesi & GOM GC185 & 16S: GU068280 & $16 S$ \\
\hline 138.BH & Seepiophila jonesi & GOM GC185 & 16S: GU068281 & $16 \mathrm{~S}$ \\
\hline 139.GC234 & Seepiophila jonesi & GOM GC234 & 16S: GU068282 & $16 \mathrm{~S}$ \\
\hline 140. GC234 & Seepiophila jonesi & GOM GC234 & 16S: GU068283 & $16 \mathrm{~S}$ \\
\hline 141.GB647 & Seepiophila jonesi & GOM GB647 & $\begin{array}{l}\text { 16S: GU068284 } \\
\text { COI: GU059186 }\end{array}$ & $16 \mathrm{~S} / \mathrm{COI}$ \\
\hline 142.GB647 & Seepiophila jonesi & GOM GB647 & 16S: GU068285 & $16 \mathrm{~S}$ \\
\hline 143.GB647 & Seepiophila jonesi & GOM GB647 & $\begin{array}{l}\text { 16S: GU068286 } \\
\text { COI: GU059187 }\end{array}$ & $16 \mathrm{~S} / \mathrm{COI}$ \\
\hline 144.GB647 & Seepiophila jonesi & GOM GB647 & $\begin{array}{l}\text { 16S: GU068287 } \\
\text { COI: GU059188 }\end{array}$ & $16 \mathrm{~S} / \mathrm{COI}$ \\
\hline 145.AC818 & Escarpia laminata & GOM AC818 & $\begin{array}{l}\text { 16S: GU068288 } \\
\text { COI: GU059189 }\end{array}$ & $16 S / C O I$ \\
\hline 146.BH & Seepiophila jonesi & GOM GC185 & 16S: GU068289 & $16 S$ \\
\hline 147.GB647 & Seepiophila jonesi & GOM GB647 & COI: GU059190 & $\mathrm{COI}$ \\
\hline 148.GB647 & Seepiophila jonesi & GOM GB647 & COI: GU059191 & $\mathrm{COI}$ \\
\hline 149.AC601 & Escarpia laminata & GOM AC601 & COI: GU059248 & $\mathrm{COI}$ \\
\hline 151.GB697 & Lamellibrachia luymesi & GOM GB697 & COI: GU059250 & $\mathrm{COI}$ \\
\hline 152.GC234 & Lamellibrachia luymesi/sp. 1 & GOM GC234 & COI: GU059253 & $\mathrm{COI}$ \\
\hline 153.GC600 & Lamellibrachia luymesi/sp. 1 & GOM GC600 & COI: GU059254 & $\mathrm{COI}$ \\
\hline 154.NewEscarpidGB485 & Escarpiid sp. nov. & GOM GB425 & $\begin{array}{l}\text { 16S: GU068290 } \\
\text { COI: GU059255 }\end{array}$ & $16 \mathrm{~S} / \mathrm{COI}$ \\
\hline 155.NewEscarpidGC234 & Escarpiid sp. nov. & GOM GC234 & $\begin{array}{l}\text { 16S: GU068291 } \\
\text { COI: GU059256 }\end{array}$ & $16 \mathrm{~S} / \mathrm{COI}$ \\
\hline 157.L. sp. 1 GB697 & Lamellibrachia luymesi/sp. 1 & GOM GB697 & COI: GU059229 & $\mathrm{COI}$ \\
\hline 159.GB697 & Seepiophila jonesi & GOM GB697 & COI: GU059251 & $\mathrm{COI}$ \\
\hline 160.GB697 & Seepiophila jonesi & GOM GB697 & COI: GU059252 & $\mathrm{COI}$ \\
\hline 161.GC234 & Lamellibrachia luymesi/sp. 1 & GOM GC234 & $\mathrm{xxx}-\mathrm{xxx}$ & $\mathrm{COI}$ \\
\hline 162.GC600 & Lamellibrachia luymesi/sp. 1 & GOM GC600 & $\mathrm{xxx}-\mathrm{xxx}$ & $\mathrm{COI}$ \\
\hline 165.GC852 & Lamellibrachia sp. 2 & GOM GC852 & $x x x-x x x$ & $\mathrm{COI}$ \\
\hline 166.L.sp1 АТ340 & Lamellibrachia luymesi/sp. 1 & GOM АT340 & $x x x-x x x$ & $\mathrm{COI}$ \\
\hline S. jonesi $\mathrm{BH}$ & Seepiophila jonesi & GOM GC185 & AF317287 & $\mathrm{COI}$ \\
\hline S. jonesi GB425 & Seepiophila jonesi & GOM GB425 & AF317288 & $\mathrm{COI}$ \\
\hline
\end{tabular}




\begin{tabular}{|c|c|c|c|c|}
\hline Sample $^{a}$ & Clade & Location $^{\mathrm{b}}$ & GenBank Accession \# & Genes \\
\hline Lamluymesi GC234 & Lamellibrachia luymesi & GOM GC234 & AY129136 & COI \\
\hline Basibranchia mariana 1 & Basibranchia mariana & West Pacific & U74078 & COI \\
\hline Arcovestia & Arcovestia ivanovi & West Pacific & AB073491 & $\mathrm{COI}$ \\
\hline E. laminata & Escarpia laminata & West Atlantic & U74063 & $\mathrm{COI}$ \\
\hline E. southwardae 1 & Escarpia southwardae & West Africa & AY326304 & $\mathrm{COI}$ \\
\hline E. southwardae 2 & Escarpia southwardae & West Africa & AY326303 & $\mathrm{COI}$ \\
\hline E. spicata & Escarpia spicata & East Pacific & U84262 & COI \\
\hline L. sp.1_b & Lamellibrachia luymesi/sp. 1 & GOM AT340 & U74061 & $\mathrm{COI}$ \\
\hline OasisiaHaploA & Oasisia alvinae & East Pacific & AY646001 & $\mathrm{COI}$ \\
\hline OasisiaHaploP & Oasisia alvinae & East Pacific & AY646016 & COI \\
\hline Lam.2000Nanaki & Lamellibrachia sp. & West Pacific & D50592 & $\mathrm{COI}$ \\
\hline Lam.300Sagami & Lamellibrachia sp. & West Pacific & АВ088674 & $\mathrm{COI}$ \\
\hline Lam.300Sagami 1 & Lamellibrachia sp. & West Pacific & D38029 & $\mathrm{COI}$ \\
\hline Lam.barhami10b & Lamellibrachia barhami & East Pacific & AY129137 & COI \\
\hline Lam.barhami11b & Lamellibrachia barhami & East Pacific & AY129138 & $\mathrm{COI}$ \\
\hline Lam.barhami4b & Lamellibrachia barhami & East Pacific & AY129147 & $\mathrm{COI}$ \\
\hline Lam.barhami7 & Lamellibrachia barhami & East Pacific & AY129146 & $\mathrm{COI}$ \\
\hline Lam.barhami8b & Lamellibrachia barhami & East Pacific & AY129145 & $\mathrm{COI}$ \\
\hline Lam.barhami9 & Lamellibrachia barhami & East Pacific & AY129141 & $\mathrm{COI}$ \\
\hline Lam.barhamib & Lamellibrachia barhami & East Pacific & U74054 & $\mathrm{COI}$ \\
\hline L. barhami2 & Lamellibrachia barhami & East Pacific & AF315045 & $16 S$ \\
\hline L. barhami3 & Lamellibrachia barhami & East Pacific & AF315045 & $16 S$ \\
\hline Lam.columna & Lamellibrachia columna & West Pacific & U74061 & $\mathrm{COI}$ \\
\hline Lam.columna 1 & Lamellibrachia columna & West Pacific & AB055210 & $\mathrm{COI}$ \\
\hline Lam.juni & Lamellibrachia juni & West Pacific & AB242858 & $\mathrm{COI}$ \\
\hline Lam.juniHaplo1 & Lamellibrachia juni & West Pacific & AB264601 & $\mathrm{COI}$ \\
\hline Lam.juniHaplo2 & Lamellibrachia juni & West Pacific & AB264602 & $\mathrm{COI}$ \\
\hline Lam.juniHaplo3 & Lamellibrachia juni & West Pacific & AB264603 & $\mathrm{COI}$ \\
\hline Lam.juniHaplo4 & Lamellibrachia juni & West Pacific & AB264604 & $\mathrm{COI}$ \\
\hline Lam.juniHaplo5 & Lamellibrachia juni & West Pacific & AB264605 & COI \\
\hline LamL4 & Lamellibrachia sp. & West Pacific & AB055209 & $\mathrm{COI}$ \\
\hline LamL5 & Lamellibrachia sp. & West Pacific & AB055210 & $\mathrm{COI}$ \\
\hline LamL6 & Lamellibrachia sp. & West Pacific & $\mathrm{AB} 088674$ & $\mathrm{COI}$ \\
\hline LamL7 & Lamellibrachia sp. & West Pacific & AB088675 & $\mathrm{COI}$ \\
\hline LamluymesiBH 2 & Lamellibrachia luymesi & GOM GC185 & AY129133 & COI \\
\hline Lam.luymesiBHb & Lamellibrachia luymesi & GOM GC185 & AY129132 & COI \\
\hline Lam.luymesiBP & Lamellibrachia luymesi & GOM GC233 & AY129139 & $\mathrm{COI}$ \\
\hline Lam.luymesiGB4252 & Lamellibrachia luymesi & GOM GB425 & AY129135 & $\mathrm{COI}$ \\
\hline Lam.luymesiGC354 & Lamellibrachia luymesi & GOM GC354 & AY129126 & $\mathrm{COI}$ \\
\hline Lam.luymesi VK & Lamellibrachia luymesi & GOM VK826 & AY129124 & COI \\
\hline Lam.Med & Lamellibrachia sp. from Med. & Mediterranean & EU046616 & $\mathrm{COI}$ \\
\hline Lam.satsumab & Lamellibrachia satsuma & West Pacific & AF342671 & $\mathrm{COI}$ \\
\hline NewEscarpiidGB425 & Escarpiid sp. nov. & GOM GB425 & AY129134 & COI \\
\hline Oaisisia fujikurai & Oasisia fujikurai & South/West Pacific & AB242857 & $\mathrm{COI}$ \\
\hline Paraescarpia & Paraescarpia cf. echinospica & West Pacific & D50594 & $\mathrm{COI}$ \\
\hline Ridgeia & Ridgeia piscesae & Juan de Fuca Ridge & AF022233 & $\mathrm{COI}$ \\
\hline Ridgeia & Ridgeia piscesae & Juan de Fuca Ridge & AF315054 & $16 S$ \\
\hline Ridgeia 2 & Ridgeia piscesae & Juan de Fuca Ridge & AF315051 & $16 S$ \\
\hline Ridgeia3 & Ridgeia piscesae & Juan de Fuca Ridge & AF315054 & $16 \mathrm{~S}$ \\
\hline Riftia & Riftia pachyptila & East Pacific & AY645989 & $\mathrm{COI}$ \\
\hline \multirow[t]{2}{*}{ Tevnia jerichonana } & Tevnia jerichonana & East Pacific & 16S: AF315042 & \\
\hline & & & COI: AY645995 & $16 \mathrm{~S} / \mathrm{COI}$ \\
\hline S. jonesi BH & Seepiophila jonesi & GOM GC185 & AF317287 & COI \\
\hline S. jonesi GB425 & Seepiophila jonesi & GOM GB425 & AF317288 & $\mathrm{COI}$ \\
\hline
\end{tabular}

a Samples analyzed for this study are numbered and labeled as for Figs. 2 and 3. Sequences from Genbank are listed by names assigned in Genbank.

b Samples from the Gulf of Mexico are indicated by GOM followed by the abbreviation of their collection sites. VK826, GC185, GC233, GB425, GC234, and GC354 are all on the upper Louisiana slope at depths $<800 \mathrm{~m}$. The other GOM sites are at depths $>900 \mathrm{~m}$ and are indicated on Fig. 1 .

the species' boundaries for Lamellibrachia, Escarpia, and Seepiophila, and we do not infer higher level phylogenetic relationships among genera because neither $16 \mathrm{~S}$ nor COI offers sufficient resolution at deeper nodes. The complete and aligned COI dataset included $690 \mathrm{bp}$, of which 460 were invariant sites, 207 were phylogenetically informative sites, and 23 were autapomorphies.

The complete $16 \mathrm{~S}$ dataset consisted of 133 sequences (see Table 1 for the complete list of samples), 127 of which were from the Gulf of Mexico. Sequences from the vent-dwelling genera Tevnia and Ridgeia were used as outgroups. The aligned 16S dataset consisted of $524 \mathrm{bp}$, of which 433 were invariant sites, 72 were phylogenetically informative, and 19 were autapomorphies.
MP, ML, and NJ analyses produced congruent trees, and the GARLI ML phylogeny is presented in Fig. $2 \mathrm{~A}$ and $\mathrm{B}$ and $3 \mathrm{~A}$ and $\mathrm{B}$.

Both $16 \mathrm{~S}$ and COI phylogenies identify five distinct monophyletic clades of vestimentiferans in the Gulf of Mexico. Four of the clades represent single morphospecies, S. jonesi, E. laminata, Lamellibrachia sp. 2, and escarpiid sp. nov., from the upper slope. However, the fifth clade includes both Lamellibrachia sp. 1 from the collections in the deeper GOM and L. luymesi from the upper Louisiana slope sites. They were, therefore, considered a single species when within- and between-species distances for the $16 \mathrm{~S}$ and COI datasets were estimated. Additionally, COI sequences of E. laminata did not differ from those of E. spicata and 
(A)

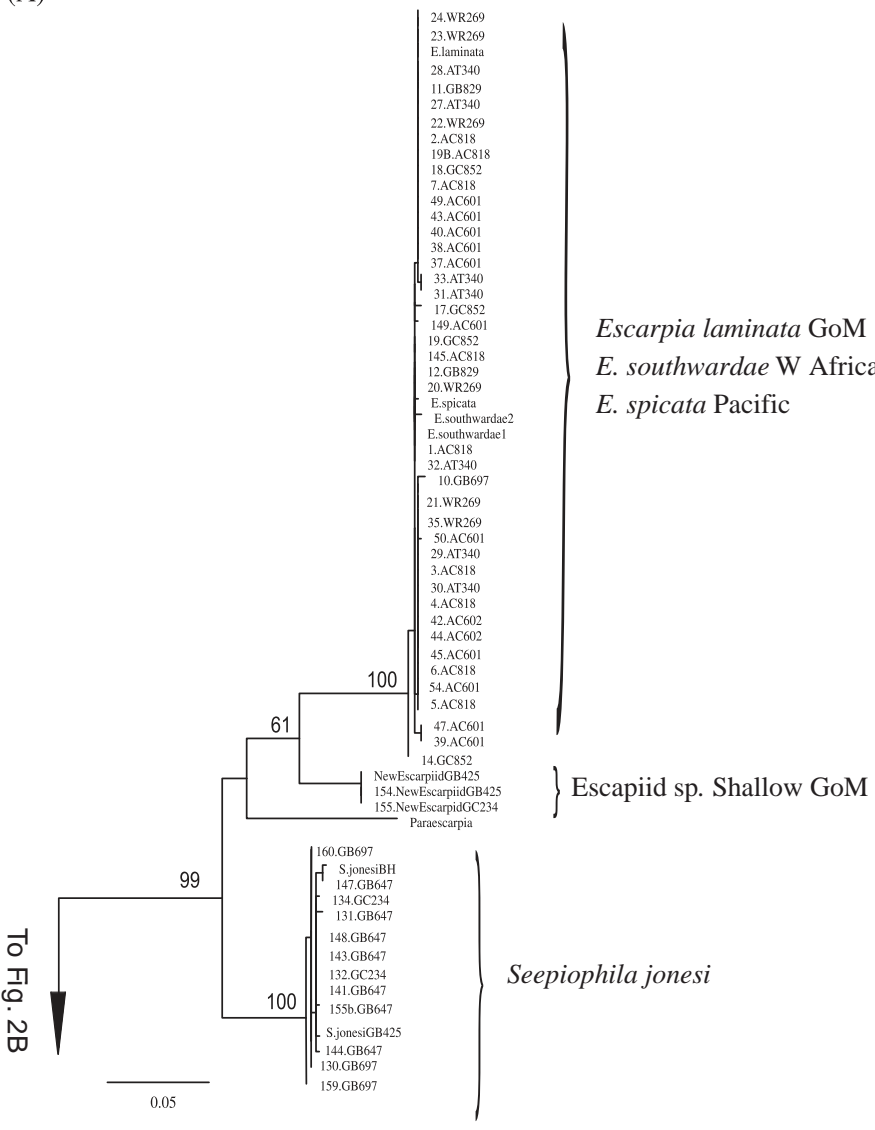

(B)

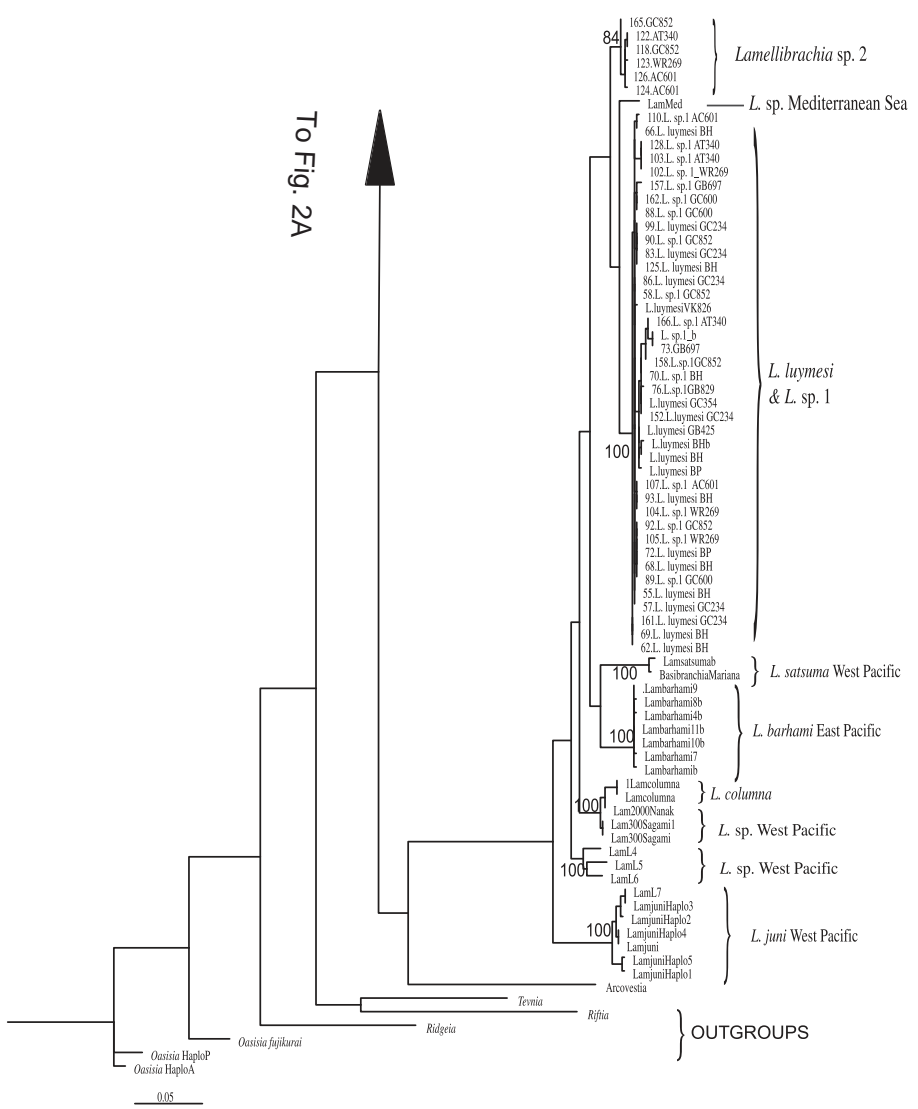

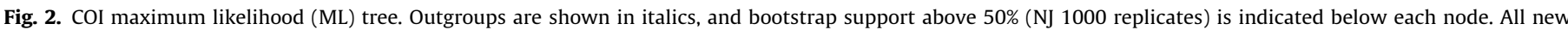

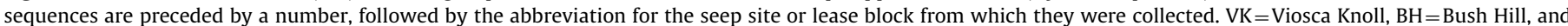

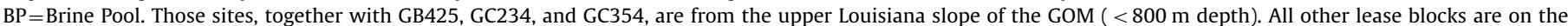
lower slope (Fig. 1).

Table 2

$16 \mathrm{~S}$ Between- and within-species (in bold, on diagonal) $p$ distances for the $16 \mathrm{~S}$ gene of the GOM species.

$[1](\%) \quad[2](\%) \quad[3](\%) \quad[4](\%) \quad[5](\%)$

\begin{tabular}{llllll} 
[1] E. laminata & $\mathbf{0 . 1 0}$ & & & & \\
[2] L. luymesi/ sp. 1 & 9.60 & $\mathbf{0 . 0 0}$ & & & \\
[3] L. sp. 2 & 9.00 & 2.20 & $\mathbf{0 . 1 0}$ & & \\
[4] S. jonesi & 2.00 & 8.40 & 8.10 & $\mathbf{0 . 0 0}$ & \\
[5] Escarpid sp. new & 3.50 & 8.30 & 8.90 & 3.70 & $\mathbf{0 . 0 0}$ \\
\hline
\end{tabular}

Table 3

Between- and within-species (in bold, on diagonal) $p$ distances for the COI gene.

$[1](\%) \quad[2](\%)$ [3] (\%) [4] (\%) [5] (\%)

\begin{tabular}{lrrrrr} 
[1] E. laminata/southwardae/spicata & $\mathbf{0 . 9}$ & & & & \\
[2] L. luymesi/ sp. 1 & 13.7 & $\mathbf{0 . 4}$ & & & \\
[3] L. sp. 2 & 13.8 & 2.8 & $\mathbf{0 . 3}$ & & \\
[4] S. jonesi & 9.7 & 14.2 & 14.4 & $\mathbf{0 . 3}$ & \\
[5] Escarpid sp. new & 7.1 & 14.8 & 14.6 & 7.1 & $\mathbf{0 . 0}$ \\
\hline
\end{tabular}

E. southwardae from the East Pacific and East Atlantic, respectively. We were unable to obtain $16 \mathrm{~S}$ sequences for $E$. spicata or $E$. southwardae.

Estimates of within- and between-species diversity $(p)$ for both genes are shown in Tables 2 and 3. Within a species, $p$ distances range from $0 \%$ to $0.1 \%$ for $16 \mathrm{~S}$ and $0 \%$ to $0.9 \%$ for the more variable
COI. The very low values for the undescribed escarpiid may reflect the small number of individuals of this species analyzed ( $n=3$ for COI and $n=2$ for 16 S).

\section{Discussion}

\subsection{Distribution of vestimentiferan species in the Gulf of Mexico and relation to other seep species}

Vestimentiferans have been collected from both hydrothermal vent and cold-seep sites. The vent and seep species fall into two different clades. However, it should be noted that "seep species" are sometimes found in sedimented hydrothermal vent areas with low levels of diffuse flow, and that "cold-seep" fluids may have temperatures elevated over background (Black et al., 1998; Kojima et al., 1997; MacDonald et al., 2000; Joye et al., 2005); so this separation really reflects more aspects of their habitat than temperature alone. Vestimentiferans found at cold seeps worldwide can be further divided into two clades. One clade includes at least five named and three unnamed species in the genus Lamellibrachia. The other clade includes three named species in the genus Escarpia, S. jonesi, Paraescarpia echinospica, and a rarely collected species (escarpiid sp. nov.) from the shallow GOM. Although Arcovestia seems basal to the Lamellibrachia clade (Fig. 2B), this position is not well supported.

Three species in the escarpiid clade of seep vestimentiferans are found in the GOM: S. jonesi has been collected from numerous sites, 
(A)

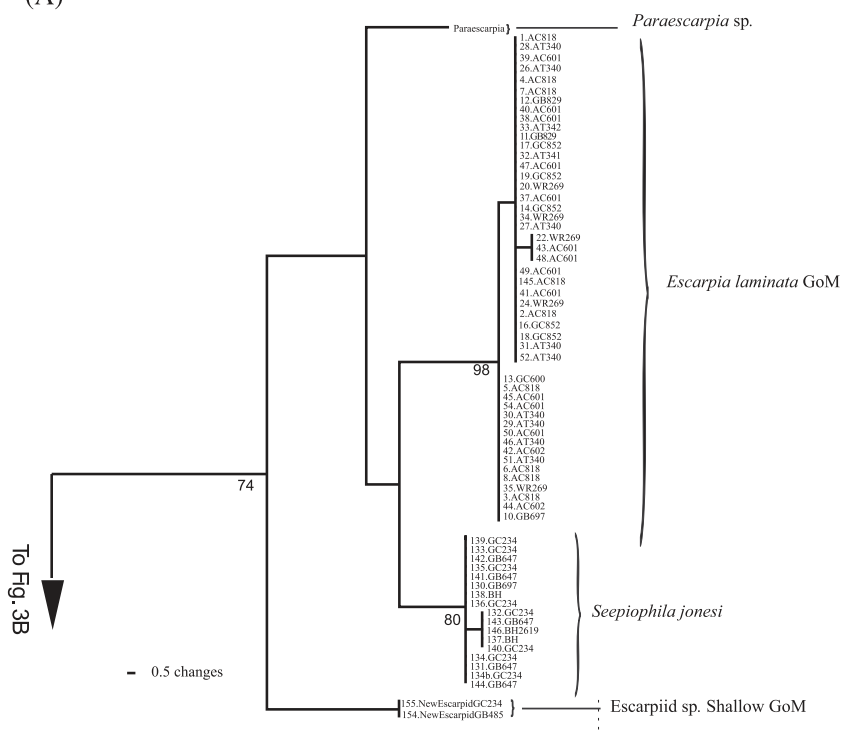

(B)

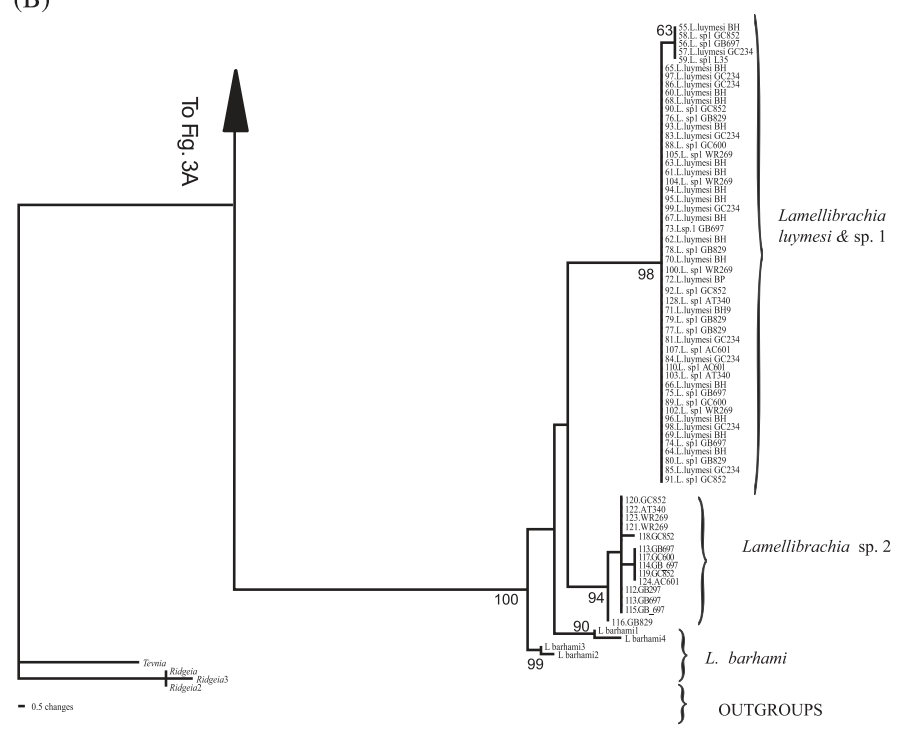

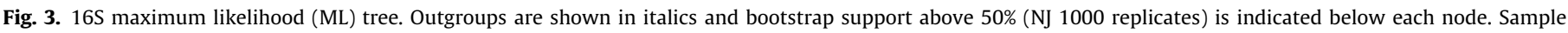
identifications and abbreviations are as in Fig. 2.

ranging in depth from 500 to $950 \mathrm{~m}$; escarpiid sp. nov. from two sites ranging in depth from 600 to $640 \mathrm{~m}$, where it co-occurs with $S$. jonesi (although it has been reported also from GC234 at $525 \mathrm{~m}$; see Cordes et al., 2003); and E. laminata from 950 to $3200 \mathrm{~m}$ depth. $S$. jonesi and E. laminata co-occurred at only one site, GB647, at a depth of $950 \mathrm{~m}$. The undescribed escarpiid differs morphologically from $S$. jonesi, as it lacks the curl of the ventral vestimental fold that is a defining character of the genus Seepiophila (Gardiner et al., 2001). Additionally, the obturacular process of the undescribed escarpiid forms a spike, whereas it is flat in $S$. jonesi and barely protrudes from the top of the obturaculum.

Both the COI and 16S phylogenetic trees distinguish these three species and place them within the escarpiid clade of seep vestimentiferans (Figs. 2 and 3). Both the $16 \mathrm{~S}$ tree and the $16 \mathrm{~S} p$ distance matrix suggest $E$. laminata is more closely related to $S$. jonesi (between-species uncorrected $p=2 \%$ ) than to the undescribed escarpiid (between-species uncorrected $p=3.50 \%$ ). However, the COI tree groups the undescribed escarpiid with the described Escarpia spp. The bootstrap value based on COI data supporting this clade is low (61\%), and the grouping observed for the $16 \mathrm{~S}$ dataset has a bootstrap below $50 \%$. Neither tree allows us to state clearly whether this new escapiid is more closely related to Escarpia, Paraescarpia, or Seepiophila.

As previously noted by other authors, COI does not separate Escarpia southwardae, E. spicata, and E. laminata, respectively, from cold seeps on the west coast of Africa in the eastern Atlantic, Guaymas Basin, off the coast of Mexico, and the GOM (Black et al., 1998). Also, there is very little to no intra-clade diversity within this group (Table 3 ). This result may indicate that those three nominal species represent a single genealogical species with a surprisingly wide geographic distribution and variable morphology. However, this assumption would require a high level of gene flow between quite distant localities, especially since the closing of the Isthmus of Panama 3.5 million years ago, followed the closing of the deep sea exchange 10 million years ago (Burton et al., 1997). This level of genetic exchange over these distances seems quite unlikely, considering what is known about larval development times for vestimentiferans (Marsh et al. 2001, Young et al., 1996). Although the life span of Escarpia larvae has not been determined, the larval life span of the vent species Riftia pachyptila is estimated at about three weeks (Marsh et al., 2001) and the larval life span of the seep vestimentiferan $L$. luymesi is estimated to be about one month (Young et al., 1996). Tyler and Young (1999) estimate that the maximal dispersal distances for these species are on the order of $60 \mathrm{~km}$ per generation, which is unlikely to support the level of genetic mixing necessary to maintain genetic homogeneity among the three described species of Escarpia from such widely separated geographic locations. It is possible, however, that undiscovered seeps around South America could connect all of these species.

The lack of fixed COI differences within Escarpia spicata, E. laminata, and E. southwardae could also be due to different rates of evolution of the COI gene in different taxa. COI has been used for higher level phylogenetic reconstructions in other groups of annelids (Halanych and Janosik, 2006) and has been adopted as an appropriate gene for the "barcode of life" for animals in general by the barcode of life initiative (BOLI; http://www.dnabarcodes. org/). However, the fact that COI fails to identify morphologically distinct populations of Escarpia from such widely separated areas implies that in this clade the mutation rate may be considerably slower than in other lineages. Slower rates of evolution in the mitochondrial DNA have been recognized in some other groups, such as the cnidarian class Anthozoa, where this phenomenon has been linked to an especially efficient repair system of their mitochondrial DNA (France and Hoover, 2002; Pont-Kingdon et al., 1998); however, no evidence of a similar system has been found in vestimentiferan mitochondrial DNA. Seep vestimentiferans can also be extremely long-lived (Bergquist et al., 2000; Cordes et al., 2007a), which may contribute to a slower rate of change of mitochondrial DNA (see for example Nabholz et al. (2008) for a consideration of longevity effects on mitochondrial rates of evolution in vertebrates).

In the COI dataset, the Lamellibrachia clade is divided into eight distinct groups that represent presumptive species, including five basal species ( $L$. juni, L. barhami, $L$. satsuma, $L$. sp. Japan, and $L$. sp. West Pacific), all of which are from the Pacific Ocean and four of which are from the western Pacific. This observation is consistent with the hypothesis that the genus Lamellibrachia originated in the Pacific, likely the western Pacific, and subsequently radiated to the eastern Pacific, the Atlantic, and the GOM.

Three morphological species of Lamellibrachia were identified in collections from the GOM: L. luymesi, from the upper slope at 
between about $400 \mathrm{~m}$ and $800 \mathrm{~m}$; L. sp. 1, from 950 to $2320 \mathrm{~m}$; and L. sp. 2, from 1175 to $2320 \mathrm{~m}$. L. luymesi and L. sp. 1 have a similar number of sheath lamellae, but the deep-water $L$. sp. 1 generally has more gill lamellae, ranging between 21 and 27 in the 28 individuals examined, whereas the shallow-water L. luymesi has between 15 and 22 gill lamellae in the 20 individuals examined for the species description. The morphological character that allowed rapid identification of animals aboardship was the relatively short and fat vestimentum of $L$. sp. 1 . The ratio of length to width of the vestimentum of $L$. sp. 1 ranges from 2.4 to 4.7 and from 6.2 to 16.4 in L. luymesi. L. sp. 2 has a similar number of sheath and gill lamellae as $L$. sp. 1 , and the vestimentum length to width ratio tends to be shorter (1.9 to 3 ). The most distinct field character for $L$. sp. 2 is the lack of a ventral vestimental fold, which is present on $L$. sp. 1 .

Despite morphological characters that distinguish the three GOM Lamellibrachia presumptive species, only either the COI or the $16 \mathrm{~S}$ phylogenetic trees resolved two of them. Specifically, both genes failed to separate $L$. luymesi from the shallow GOM and $L$. sp. 1 from the deeper GOM sites. This lack of genetic differences between individuals that span such a wide depth range is unusual (Chase et al., 1998; Zardus et al., 2006) and surprising, given the morphological differences. Both $16 \mathrm{~S}$ and COI genes consistently identify Lamellibrachia sp. 2 as a separate clade, sister to the L. luymesi/L. sp. 1 clade.

There were no apparent geographic distributional patterns that were independent of depth for the seep vestimentiferans in the Gulf of Mexico. The common species present on the upper Louisiana slope (L. luymesi and S. jonesi) have been found at both the eastern-most and western-most sites where we have collected vestimentiferans. E. laminata from the lower slope ranges from the Alaminos Canyon sites, our most westerly collection sites for this study, to the Florida Escarpment in the eastern GOM (Cordes et al., 2009; McMullin et al., 2003). Both of the Lamellibrachia spp. found at the deeper sites occurred over the entire E-W range of sites within their depth range (from the Alaminos Canyon sites in the west to AT340 in the east).

\subsection{Within-species diversity of the GOM vestimentiferans}

Tables 2 and 3 report within- and between-species $p$ distance calculated for the GOM genetic species. In most cases, withinspecies diversity for both $16 \mathrm{~S}$ and in the COI genes is strikingly low, a finding that is in contrast to previous studies on deep-sea mollusks and echinoderms, where large amounts of genetic variation were observed over small distances (Chase et al., 1998; Howell et al., 2004; Quattro et al., 2001). However, largescale studies indicate that low within-species genetic variation may be typical of deep-sea organisms (Bisol et al., 1984) and even suggest that it may decrease with increase in depth (France and Kocher, 1996). Genetic variation has been suggested to be an important feature of the genome of an organism that allows it to adapt to a changing environment (Powers et al., 1991). Organisms that live in the deep sea may experience a long-term stable environment, resulting in low levels of within-species genetic diversity. Alternatively, low within-species genetic diversity may be the result of fewer replication errors, more efficient repair in the germ line, or repeated population bottlenecks.

E. laminata, E. spicata, and E. southwardae clade and L. luymesi sp. 1 and $L$. sp. 2 have a moderate degree of intra-specific diversity (Figs. 2 and 3). However, as with all of the GOM vestimentiferans analyzed, none of the within-species clades grouped by specific geographic locations or depth. A similar pattern was found in the seep mussel Bathymodiolus childressi, which, based on markers ranging from microsatellites to mitochondrial genes, has a panmictic population in the GOM ranging across $550 \mathrm{~km}$ east to west and from 540 to $2200 \mathrm{~m}$ depth (Carney et al., 2006; Cordes et al., 2007b). In contrast, genetic breaks and barriers that restrict gene flow were identified in both hydrothermal vent vestimentiferans and mussels along the East Pacific Rise (EPR). Specifically, Won et al. (2003) used COI sequences to identify two highly divergent clades on the EPR on the two sides of the Easter Island Microplate. Similarly, Hurtado et al. (2004) used COI sequences to identify several geographic breaks and barriers that restrict gene flow in three genera of annelids along the EPR, including two species of vestimentiferan (Riftia pachypitla and Tevnia jerichonana).

\section{Summary}

In this study, our primary goals were to identify and characterize the distributions of vestimentiferans at seep sites covering a wide geographic and depth range in the Gulf of Mexico and to investigate their relationship to other seep vestimentiferan species, using phylogenetic analysis of mitochondrial gene sequences. Although the genetic analyses confirmed identification of most of the morphological species during collections, we also identified an unexpected discrepancy between the morphospecies identified during the collections and genealogical species identified using the mitochondrial genes COI and 16S. Using morphological characters, we identified two new species of Lamellibrachia (spp. 1 and 2). However, neither COI nor 16S distinguished the deeper occurring morphospecies $L$. sp. 1 from L. luymesi, the common Lamellibrachia species on the upper Louisiana slope. Our molecular genetic analyses confirm the presence of three vestimentiferan species within the escarpiid clade in the Gulf of Mexico. However, since COI also does not differentiate between E. laminata found in the Gulf of Mexico and the other described Escarpia species off the coast of Africa or in the eastern Pacific Ocean, we suggest that COI or $16 \mathrm{~S}$ genes may not reliably distinguish closely related species of long-lived seep vestimentiferans. We are currently evaluating the usefulness of several nuclear genes to clarify the relationships among the named species of Escarpia and the Lamellibrachia species in the Gulf of Mexico.

\section{Acknowledgments}

This work was funded by a subcontract to Bureau of Ocean Energy Management, Regulation and Enforcement (BOEMRE) contract \#1435-01-05-39187, "Investigations of Chemosynthetic Communities on the Lower Continental Slope of the Gulf of Mexico (Chemo III)," with vessel and submergence facilities support provided by National Oceanic and Atmospheric Administration's Office of Ocean Exploration and Research. This study would not have been possible without the support and expertise of the captains, crews, and expedition leaders of the Research Vessel Atlantis, the DSV ALVIN, the NOAA ship Ronald Brown, and the ROV JASON II. The authors are grateful to Erik Cordes and Erin Becker for help at sea, to Stephanie Lessard-Pilon, Erin Becker, and Meredith Cole Patterson for help in the laboratory, to Erin McMullin for sharing DNA and expertise, and to A. Faucci and ChEss Siboglinidae Workshop participants for suggestions and helpful discussion.

\section{References}

Bergquist, D.C., Urcuyo, I.A., Fisher, C.R., 2002. Establishment and persistence of seep vestimentiferan aggregations on the upper Louisiana slope of the Gulf of Mexico. Marine Ecology-Progress Series 241, 89-98.

Bergquist, D.C., Williams, F.M., Fisher, C.R., 2000. Longevity record for deep-sea invertebrate. Nature 403 (6769), 499-500.

Bisol, P.M., Costa, R., Sibuet, M., 1984. Ecological and genetic survey on two deep-sea holothurians - benthogone-rosea and benthodytes-typica. Marine Ecology_Progress Series 15 (3), 275-281. 
Black, M.B., Trivedi, A., Maas, P.A.Y., Lutz, R.A., Vrijenhoek, R.C., 1998. Population genetics and biogeography of vestimentiferan tube worms. Deep-Sea Research II: Topical Studies in Oceanography 45, 1-3.

Burton, K.W., Ling, H.F., Onions, R.K., 1997. Closure of the Central American Isthmus and its effect on deep-water formation in the North Atlantic. Nature 386 (6623), 382-385.

Carney, S.L., Formica, M.I., Divatia, H., Nelson, K., Fisher, C.R., Schaeffer, S.W., 2006 Population structure of the mussel "Bathymodiolus" childressi from Gulf of Mexico hydrocarbon seeps. Deep-Sea Research I: Oceanographic Research Papers 53 (6), 1061-1072.

Chase, M.R., Etter, R.J., Rex, M.A., Quattro, J.M., 1998. Bathymetric patterns of genetic variation in a deep-sea protobranch bivalve, Deminucula atacellana. Marine Biology 131 (2), 301-308.

Cordes, E.E., Bergquist, D.C., Fisher, C.R., 2009. Macro-ecology of Gulf of Mexico cold seeps. Annual Review of Marine Science 1, 143-168.

Cordes, E.E., Bergquist, D.C., Redding, M.L., Fisher, C.R., 2007a. Patterns of growth in cold-seep vestimenferans including Seepiophila jonesi: a second species of longlived tubeworm. Marine Ecology-An Evolutionary Perspective 28 (1), 160-168

Cordes, E.E., Becker, E.L., Hourdez, S., Fisher, C.R., 2010. Influence of foundation species, depth, and location on diversity and community composition at Gulf of Mexico lower-slope cold seeps. Deep-Sea Research II: Topical Studies in Oceanography 57 (21-23), 1870-1881.

Cordes, E.E., Carney, S.L., Hourdez, S., Carney, R.S., Brooks, J.M., Fisher, C.R., 2007b. Cold seeps of the deep Gulf of Mexico: Community structure and biogeographic comparisons to Atlantic equatorial belt seep communities. Deep-Sea Research I: Oceanographic Research Papers 54 (4), 637-653.

Cordes, E.E., Bergquist, D.C., Shea, K., Fisher, C.R., 2003. Hydrogen sulfide demand of long-lived vestimentiferan tube worm aggregations modifies the chemical environment at deep-sea hydrocarbon seeps. Ecology Letters 6 (2003), 212-219.

Doyle, J.J., Doyle, J.L., 1987. A rapid DNA isolation procedure for small quantities of fresh leaf tissue. Phytochemical Bulletin 19, 11-15.

Felsenstein, J., 1985. Confidence limits on phylogenies: an approach using the bootstrap. Evolution 39 (4), 783-791.

Folmer, O., Black, M., Hoeh, W., Lutz, R., Vrijenhoek, R., 1994. DNA primers for amplification of mitochondrial cytochrome c oxidase subunit I from diverse metazoan invertebrates. Molecular Marine Biology and Biotechnology 3 (5), 294-299.

France, S.C., Hoover, L.L., 2002. DNA sequences of the mitochondrial COI gene have low levels of divergence among deep-sea octocorals (Cnidaria: Anthozoa). Hydrobiologia 471, 149-155.

France, S.C., Kocher, T.D., 1996. Geographic and bathymetric patterns of mitochondrial 16S rRNA sequence divergence among deepsea amphipods, Eurythenes gryllus. Marine Biology 126 (4), 633-643.

Gardiner, S.L., McMullin, E., Fisher, C.R., 2001. Seepiophila jonesi, a new genus and species of vestimentiferan tube worm (Annelida: Pogonophora) from hydrocarbon seep communities in the Gulf of Mexico. Proceedings of the Biologica Society of Washington 114 (3), 694-707.

Guindon, S., Gascuel, O., 2003. A simple, fast, and accurate algorithm to estimate large phylogenies by maximum likelihood. Systematic Biology 52 (5), 696-704.

Halanych, K.M., Feldman, R.A., Vrijenhoek, R.C., 2001. Molecular evidence that Sclerolinum brattstromi is closely related to vestimentiferans, not to Frenulate pogonophorans (Siboglinidae: Annelida). Biological Bulletin 201 (1), 65-75.

Halanych, K.M., Janosik, A.M., 2006. A review of molecular markers used for annelid phylogenetics. Integrative and Comparative Biology 46 (4), 533-543.

Howell, K.L., Rogers, A.D., Tyler, P.A., Billett, D.S.M., 2004. Reproductive isolation among morphotypes of the Atlantic seastar species Zoroaster fulgens (Asteroidea : Echinodermata). Marine Biology 144 (5), 977-984.

Hurtado, L.A., Lutz, R.A., Vrijenhoek, R.C., 2004. Distinct patterns of genetic differentiation among annelids of eastern Pacific hydrothermal vents. Molecular Ecology 13 (9), 2603-2615.

Joye, S.B., MacDonald, I.R., Montoya, J.P., Peccini, M., 2005. Geophysical and geochemical signatures of Gulf of Mexico seafloor brines. Biogeosciences 2, 1-15.

Kojima, S., Ohta, S., Yamamoto, T., Miura, T., Fujiwara, Y., Fujikura, K., Hashimoto, J. 2002. Molecular taxonomy of vestimentiferans of the western Pacific and thei phylogenetic relationship to species of the eastern Pacific-II-Families Escarpiidae and Arcovestiidae. Marine Biology 141 (1), 57-64.

Kojima, S., Segawa, R., Hashimoto, J., Ohta, S., 1997. Molecular phylogeny of vestimentiferans collected around Japan, revealed by the nucleotide sequences of mitochondrial DNA. Marine Biology 127 (3), 507-513.

Kojima, S., Segawa, R., Kobayashi, T., Hashimoto, T., Fujikura, K., Hashimoto, J. Ohta, S., 1995. Phylogenetic relationships among species of Calyptogena (bivalvia, vesicomyidae) collected around Japan revealed by nucleotide sequences of mitochondrial genes. Marine Biology 122 (3), 401-407.

MacDonald, I.R., Buthman, D., Sager, W.W., Peccini, M.B., Guinasso Jr., N.R., 2000 Pulsed oil discharge from a mud volcano. Geology 28 (10), 907-910.

Maddison, D.R., Maddison, W.P., 2000. MacClade 4: Analysis of Phylogeny and Character Evolution. Sinauer Associates Inc., Sunderland, MA, USA

Marsh, A.G., Mullineaux, L.S., Young, C.M., Manahan, D.T., 2001. Larval dispersal potential of the tubeworm Riftia pachyptila at deep-sea hydrothermal vents. Nature 411 (6833), 77-80.

McMullin, E.R., Hourdez, S., Schaeffer, S.W., Fisher, C.R., 2003. Phylogeny and biogeography of deep sea vestimentiferan tubeworms and their bacterial symbionts. Symbiosis 34 (1), 1-41.

Mironov, A.N., 2000. New taxa of stalked crinoids from the suborder Bourgueticrinina (Echinodermata, Crinoidea). Zoologichesky Zhurnal 79 (6), 712-728.

Miura, T., Nedachi, M., Hashimoto, A., 2002. Sulphur sources for chemoautotrophic nutrition of shallow water vestimentiferan tubeworms in Kagoshima Bay. Journal of the Marine Biological Association of the United Kingdom 82 (4), 537-540.

Nabholz, B., Glemin, S., Galtier, N., 2008. Strong variations of mitochondrial mutation rate across mammals - the longevity hypothesis. Molecular Biology and Evolution 25 (1), 120-130.

Palumbi, S.R., Warner, R.R., 2003. Ecology. Why gobies are like Hobbits. Science 299 (5603), 51-52.

Pont-Kingdon, G., Okada, N.A., Macfarlane, J.L., Beagley, C.T., Watkins-Sims, C.D. Cavalier-Smith, T., Clark-Walker, G.D., Wolstenholme, D.R., 1998. Mitochondrial DNA of the coral Sarcophyton glaucum contains a gene for a homologue of bacterial MutS: a possible case of gene transfer from the nucleus to the mitochondrion. Journal of Molecular Evolution 46 (4), 419-431.

Posada, D., 2003. Using MODELTEST and PAUP* to select a model of nucleotide substitution. Current Protocols for Bioinformatics, Unit 6, 5 Chapter 6 .

Posada, D., Crandall, K.A., 1998. MODELTEST: testing the model of DNA substitution. Bioinformatics 14 (9), 817-818.

Powers, D.A., Lauerman, T., Crawford, D., DiMichele, L., 1991. Genetic mechanisms for adapting to a changing environment. Annual Review of Genetics 25, 629-659.

Quattro, J.M., Chase, M.R., Rex, M.A., Greig, T.W., Etter, R.J., 2001. Extreme mitochondrial DNA divergence within populations of the deep-sea gastropod Frigidoalvania brychia. Marine Biology 139 (6), 1107-1113.

Rouse, G., 2001. A cladistic analysis of Siboglinidae caullery, 1914 (Polychaeta, Annelida): formerly the phyla pogonophora and vestimentifera. Zoological Journal of the Linnean Society $132,55-80$.

Saitou, N., Nei, M., 1987. The neighbor-joining method: a new method for reconstructing phylogenetic trees. Molecular and Biological Evolution 4, 406-425.

Tamura, K., Dudley, J., Nei, M., Kumar, S., 2007. MEGA4: molecular evolutionary genetics analysis (MEGA) software version 4.0. Molecular Biology and Evolution 24 (8), 1596-1599.

Thompson, J.D., Gibson, T.J., Higgins, D.G., 2002. Multiple sequence alignment using ClustalW and ClustalX. Current Protocols in Bioinformatics, Chapter 2. Unit 23.

Thornhill, D.J., Mahon, A.R., Norenburg, J.L., Halanych, K.M., 2008. Open-ocean barriers to dispersal: a test case with the Antarctic Polar Front and the ribbon worm Parborlasia corrugatus (Nemertea: Lineidae). Molecular Ecology 17 (23), 5104-5117.

Tyler, P.A., Young, C.M., 1999. Reproduction and dispersal at vents and cold seeps. Journal of the Marine Biological Association of the United Kingdom 79, 193-208.

van der Land, J., Narrevang, A., 1975. The systematic position of Lamellibrachia [sic] (annelida, vestimentifera). In: Norrevang, A. (Ed.), The Phylogeny and Systematic Position of Pogonophora, pp. 86-101.

Wilgenbusch, J.C., Swofford, D., 2003. Inferring evolutionary trees with PAUP*. Current Protocols in Bioinformatics, Chapter 6, Unit 64.

Won, Y., Young, C.R., Lutz, R.A., Vrijenhoek, R.C., 2003. Dispersal barriers and isolation among deep-sea mussel populations (mytilidae: Bathymodiolus) from eastern Pacific hydrothermal vents. Molecular Ecology 12 (1), 169-184.

Young, C.M., Vazquez, E., Metaxas, A., Tyler, P.A., 1996. Embryology of vestimentiferan tube worms from deep-sea methane/sulphide seeps. Nature 381 (6582), 514-516.

Zardus, J.D., Etter, R.J., Chase, M.R., Rex, M.A., Boyle, E.E., 2006. Bathymetric and geographic population structure in the pan-Atlantic deep-sea bivalve Deminucula atacellana (Schenck, 1939). Molecular Ecology 15 (3), 639-651.

Zwickl, D.J., 2006. Genetic algorithm approaches for the pylogenetic analysis of large biological sequence datasets under the maximum liklihood criterion. [www.bioutexas.edu/faculty/antisense/garli/Garli.html] Ph.D. dissertation, The University of Texas at Austin, TX, USA. 